\title{
Risk Factors of Anaemia Among Pregnant Women in Banyo Health District, Adamawa Region of Cameroon
}

\author{
Caroline Teh Monteh ${ }^{1}$, Justin Ndié ${ }^{1}$, Joëlle Laure Sobngwi ${ }^{2}$, Benjamin Alexandre Nkoum² \\ ${ }^{1}$ Division of the Operational Research in Health/Ministry of Public Health, Yaounde, Cameroon \\ ${ }^{2}$ School of Health Sciences, Catholic University of Central Africa, Yaounde, Cameroon
}

Email address:

ndjust2002@yahoo.fr (C. T. Monteh)

\section{To cite this article:}

Caroline Teh Monteh, Justin Ndié, Joëlle Laure Sobngwi, Benjamin Alexandre Nkoum. Risk Factors of Anaemia Among Pregnant Women in Banyo Health District, Adamawa Region of Cameroon. Central African Journal of Public Health. Vol. 5, No. 5, 2019 , pp. $221-226$. doi: 10.11648/j.cajph.20190505.17

Received: August 19, 2019; Accepted: September 16, 2019; Published: October 9, 2019

\begin{abstract}
Background: Anaemia in pregnant women remains a major preoccupation in the fight against maternal and infant mortality. It constitutes a sure materno-infantile morbidity and mortality risk, premature delivery and small weight births. Objective: This study was aimed at determining the risk factors of anaemia among pregnant women in the Banyo Health District in the Adamawa Region, Cameroun. Materials and methods: A cross-sectional study was carried out for six weeks (September 17 to November 3, 2013) in 6 health facilities of the Banyo Health District. Included in this study were all pregnant woman received during prenatal consultation in the health facilities of the Banyo Health District who gave her consent to participate in the study. Data collection was done with the help of a questionnaire. A total of 297 pregnant women received during prenatal consultation in the 6 health facilities of the 5 health areas were chosen by the systematic consecutive sampling method. These women benefited from a haemoglobin test after a capillary blood draw was carried out which permitted a paraclinical evaluation of the anaemia. Data were analysed by Excel and SPSS 22 softwares. Results: The results showed that the mean haemoglobin rate was of $10.8 \pm 1.89 \mathrm{~g} / \mathrm{dl} .52 .5 \%$ of pregnant women were anaemic amongst which $46 \%$ had mild anaemia, $48 \%$ had moderate anaemia and $6 \%$ had severe anaemia. $63 \%$ of the women with anaemia live in polygamous household and $55.7 \%$ do not wash their hands with soap after a meal. The prevalence of anaemia among pregnant women in the Banyo Health District was associate with the consumption of kaolin $(\mathrm{OR}=1.9$ [1.1-3.9] $\mathrm{p}=0.049)$, irregular iron supplement intake $(\mathrm{OR}=2.9$ [1.4-5.9] $\mathrm{p}=0.014)$ and the number of meal consumed per day less than or equal to $2(\mathrm{OR}=2.81$ [2.13-5.9] $\mathrm{p}=0.007)$. On the other hand, regular fruit consumption $(\mathrm{OR}=0.28[0.11-0.74] \mathrm{p}=0.011)$, sound knowledge of the causes $(\mathrm{OR}=0.36[0.19-0.68] \mathrm{p}=0.002)$ and the consequences $(\mathrm{OR}=0.35[0.19-0.7] \mathrm{p}=0.003)$ of anaemia were significantly associated with lesser risk of anaemia among the pregnant women. Conclusion: The high prevalence of anaemia among pregnant women in the Banyo Health District remains a preoccupying health problem. It demonstrates the need of a global action in resolution of this public health problem. As such, there is a need to mobilize a preventive strategy with emphasis on sensitization, nutritional and health education. In addition, maternal systematic iron supplementation from the second trimester of pregnancy remains an imperative.
\end{abstract}

Keywords: Anemia, Risk Factors, Pregnant Woman, Banyo Health District, Adamawa Region

\section{Introduction}

Anemia is a decrease in the total amount of circulating functional hemoglobin, expressed when the peripheral blood hemoglobin concentration decreases below normal values. Anemia remains the most common public health problem in the world, affecting all age groups [1-3]. It is more common in pregnant women and young children. In addition, it has a negative impact on the health of the fetus and that of the mother and still causes significant morbidity and mortality among pregnant women [4]. Indeed, according to Brabin et al. [5] and FAO [6], anemia during pregnancy is associated with increased maternal and infant morbidity and mortality, preterm birth and low birth weight. For Demmouche and Moulessehoul [7], pregnant women's anemia is frequent and 
is partly the result of the nutritional status of the population.

In developed countries, it affects $10-20 \%$ of women and more than $30-80 \%$ of women in developing countries. According to WHO [8], about 59.1 million, or $43.8 \%$ of pregnant women are globally anemic and the highest prevalence is in Africa with more than half of all people affected Territory with 18.5 million or $61.3 \%$. In Cameroon, one in two pregnant women (50\%) is anemic [9]. In the same vein, Helen Keller International [10] pointed out that $50.9 \%$ of pregnant women in Cameroon were anemic. In the Adamaoua Region, 35.8\% of women suffer from anemia [9]. According to empirical evidence and data from health facility consultation records in the Banyo Health District, four out of ten women receiving antenatal care are anemic. So, what are the risk factors for anemia in pregnant women in the Banyo
Health District? This study aims to determine the risk factors for anemia in pregnant women in the Banyo Health District, Adamaoua-Cameroon Region.

\section{Framework for the Study}

The Banyo Health District is one of eight health districts covering the Adamaoua Health Region. The town of Banyo, capital of Mayo-Banyo Division is located $582 \mathrm{Km}$ from Yaoundé. The Banyo Health District covers the Health Areas of Banyo, Sambolabo, Allat, Mayo-Darlé, Mbamti Katarko, Ndi-Wawa and Horé-Taram with an area of about $5475 \mathrm{~km}^{2}$. It is bounded on the west by Nigeria, on the east by the district of Tibati and on the north by the district of Tignere and on the south by the District of Bankim.

Table 1. Health facilities in the Banyo Health District where the survey was conducted.

\begin{tabular}{lll}
\hline Name of the health area & Health facility & Study area \\
\hline \multirow{2}{*}{ Fada } & District Hospital of Banyo & Urbain \\
Mayo-Darlé & BPH Wouroum & Urbain \\
Mbamti-Katarko & Integrated Health's Center of Mayo-Darlé & Rural \\
Tiket & Integrated Health's Center of Mbamti & Rural \\
Sambo-Labo & Integrated Health's Center of Tiket & Urbain \\
\hline
\end{tabular}

\section{Materials and Methods}

A cross-sectional study was carried out over six weeks (from 17 September to 03 November 2013) in 06 health units in the Health District of Banyo. Included in this study were any pregnant women who received prenatal consultations at a health facility in the Banyo Health District to consent to the survey. Data were collected using a questionnaire. A total of 297 pregnant women received prenatal consultations in 6 health facilities in the 5 health areas in the summer, selected according to the systematic sampling method.

A biological examination was carried out in each of the pregnant women following the information and her free and informed consent. This was a blood sample for hemoglobin using the Hemoglobinometer (URIT 12). The methodology used for the study of the hemogram was as follows: capillary blood was taken from the strips with the same numbers as those assigned to the worksheet and to the questionnaire. According to the WHO [11], the limits are respectively 13 $\mathrm{g} / \mathrm{dl}$ for men and $12 \mathrm{~g} / \mathrm{dl}$ for women and children. However, the threshold recommended for pregnant women is $11 \mathrm{~g} / \mathrm{dl}$, that is, anemia is defined during pregnancy, with a hemoglobin level of less than $11 \mathrm{~g} / \mathrm{dl}$ in the first and third trimester of the pregnancy, less than $10.5 \mathrm{~g} / \mathrm{dl}$ in the second and within the post, by a rate lower than $10 \mathrm{~g} / \mathrm{dl}$.

\section{Determination of Hemoglobin Rate}

A determination of the hemoglobin level by taking capillary blood made it possible to make the diagnosis of anemia. A drop of blood was deposited on a strip which was also introduced into the portable hemoglobinometer (URIT
12). After one minute, by simple reading, the value of the hemoglobin level in $\mathrm{g} / \mathrm{dl}$ was obtained; this value was finally recorded in the questionnaire. Thus, anemia was defined according to the WHO [11] criteria by a hemoglobin level of less than $11 \mathrm{~g} / \mathrm{dl}$ in pregnant women.

It is classified into 3 levels [11]:

a. Severe anemia if the hemoglobin level is less than 7.0 $\mathrm{g} / \mathrm{dl}$;

b. Moderate anemia if the hemoglobin level is between 7.0 $\mathrm{g} / \mathrm{dl}$ and $10 \mathrm{~g} / \mathrm{dl}$;

c. Mild anemia if hemoglobin is between $10 \mathrm{~g} / \mathrm{dl}$ and 11 $\mathrm{g} / \mathrm{dl}$.

The dependent variable in this study was anemia in pregnant women. It has the modality: anemia if the hemoglobin is less than $11 \mathrm{~g} / \mathrm{dl}$ and no anemia if the hemoglobin is greater than or equal to $11 \mathrm{~g} / \mathrm{dl}$. Subsequently, it was classified as mild anemia, moderate anemia and severe anemia according to the above WHO criteria.

The explanatory variables were grouped as follows:

a. Variables related to socio-demographic and economic characteristics: age, marital status, marital status, number of pregnancies, age at first birth, intergenerational interval, ethnicity, religion, residence, school level, principal occupation, monthly income, residential environment, source of water and number of meals per day.

b. Variables related to nutritional and health characteristics: quality of food consumed, consumption of clay, taking tea, taking intermittent preventive treatment (IPT), washing hands before meals and after the toilet.

c. Variables related to clinical characteristics: number of Antenatal Care (ANC), termination of pregnancy, net 
use, iron supplementation, HIV testing, ARV and bleeding during pregnancy.

d. Knowledge variables on anemia: this variable contains 4 weighted indicators (causes, consequences, signs and means of preventing anemia). For the assessment of the level of knowledge of women on anemia, the scores were calculated by weighting each indicator. Thus, each indicator in the explanatory variable with a graduated scale was assigned a score of 0 for the modality "not fair" or score 1 for the "just" modality. At the end, the total points are calculated on 15 . The minimum score obtained was 0 , while the maximum was 12 points. This score was used to construct the "knowledge" variable that divided individuals into two groups: women with low knowledge of anemia $(0 \leq$ note $\leq 5)$ and those with good knowledge of anemia $(6 \leq$ note $\leq 12)$.

The data was entered, processed and analyzed using CS Pro 5, Excel and SPSS software. The descriptive analysis allowed the sample to be described through central (medium or median) trends, dispersion characteristics (standard deviation), and frequency distribution of modalities as a function of the variable of interest. The cross-tabulations were used to describe the level of knowledge, attitudes and practices of claimants based on the characteristics studied, and the Pearson Chi 2 test was conducted to examine associations between variables with a significance level of $5 \%$. The logistic regression with $95 \%$ CI highlighted the risk factors for anemia in pregnant women in the Banyo Health District.

\section{Results}

Of the 297 pregnant women surveyed, the mean age was $23 \pm 5$ years and the age group most represented was 18 to 35 years $(80 \%)$. The Muslim religion (83\%) was the most dominant. $55 \%$ of respondents lived in urban areas. The majority of pregnant women $(57.7 \%)$ were out of school. The majority of the occupations were housewives (72\%). 69.9\% of women had a monthly income of less than 50,000 CFA francs. The vast majority (96\%) were married or free-union women, of whom 55\% (157) were in polygamous homes. Most women (52\%) had their first childbirth under 18 years of age. $70 \%$ of respondents were multiparous, of whom $50.6 \%$ had fewer than three pregnancies.

Regarding hygiene, the vast majority of women surveyed $(76 \%)$ did not always wash their hands before meals or after the toilets, of which $55.7 \%$ did not always wash their hands with soap. Most respondents (67.9\%) were taking three meals a day and $65.4 \%$ consumed water from an improved water source.

About the ANC, 44.2\% of women had received no ANC. Up to $37 \%$ of pregnant women took no iron supplement and only $23.6 \%$ took it daily. The majority of pregnant women (57\%) had no IPT, only $7 \%$ had taken IPT2, and $18.1 \%$ of pregnant women did not sleep under an impregnated mosquito net. $10 \%$ of women surveyed were taking antiretroviral therapy.
Regarding knowledge, $86 \%$ of women had little knowledge about the causes and consequences of anemia.

Overall, the mean hemoglobin was $10.8 \pm 1.89 \mathrm{~g} / \mathrm{dl}$ and the prevalence of anemia in pregnant women was $52.5 \%$, of which $46 \%$ had mild anemia, $48 \%$ had moderate anemia and $6 \%$ severe anemia.

Table 2. Characteristics of women and anemia in pregnancy.

\begin{tabular}{|c|c|c|c|}
\hline \multirow{2}{*}{ Caracteristics of women } & \multicolumn{2}{|c|}{ Anemia on pregnancy } & \multirow{2}{*}{ P-value } \\
\hline & Anemia n(\%) & No anemia n(\%) & \\
\hline \multicolumn{4}{|l|}{ Marital Statut } \\
\hline Maried/free union & $150(52.27)$ & $137(47.73)$ & \multirow{3}{*}{0.63} \\
\hline Single/Divorced/Widow & $6(60)$ & $4(40)$ & \\
\hline \multicolumn{3}{|l|}{ Matrimonial regime } & \\
\hline Monogamy & $68(43.31)$ & $89(56.69)$ & \multirow{3}{*}{$0.003^{*}$} \\
\hline Polygamy & $83(63.36)$ & $48(36.64)$ & \\
\hline Not concerned & $5(55.56)$ & $4(44.44)$ & \\
\hline \multicolumn{4}{|l|}{ Religion } \\
\hline Christian & $25(39.06)$ & $39(60.94)$ & \multirow{3}{*}{$0.017^{*}$} \\
\hline Muslem & $130(56.03)$ & $102(43.97)$ & \\
\hline Other religion & $1(100)$ & $0(0.0)$ & \\
\hline \multicolumn{4}{|l|}{ School Level } \\
\hline Out of school & $90(58.44)$ & $64(41.56)$ & \multirow{4}{*}{0.189} \\
\hline Primary & $44(47.31)$ & $49(52.69)$ & \\
\hline Secondary & $21(44.68)$ & $26(55.32)$ & \\
\hline Superior & $1(33.33)$ & $2(66.67)$ & \\
\hline \multicolumn{4}{|l|}{ Area of residence } \\
\hline Urban & $73(49.32)$ & $75(50.68)$ & \multirow{2}{*}{0.271} \\
\hline Rural & $83(55.70)$ & $66(44.30)$ & \\
\hline \multicolumn{4}{|l|}{ Nomber of meals par day } \\
\hline$\leq$ two meals & $43(71.67)$ & $17(28.33)$ & \multirow{2}{*}{$0.001^{*}$} \\
\hline$\geq$ three meals & $113(47.68)$ & $124(52.32)$ & \\
\hline \multicolumn{4}{|l|}{ Regular fruit consumption } \\
\hline Yes & $83(43.92)$ & $106(56.08)$ & \multirow{2}{*}{$0.000^{*}$} \\
\hline No & $73(67.59)$ & $35(32.41)$ & \\
\hline \multicolumn{4}{|l|}{ Regular milk consumption } \\
\hline Yes & $95(47.74)$ & $104(52.26)$ & \multirow{2}{*}{$0.000^{*}$} \\
\hline No & $61(62.24)$ & $37(37.76)$ & \\
\hline \multicolumn{4}{|l|}{ Regular kaolin consumption } \\
\hline Yes & $61(61.62)$ & $38(38.38)$ & \multirow{2}{*}{$0.018^{*}$} \\
\hline No & $95(47.98)$ & $103(52.02)$ & \\
\hline \multicolumn{4}{|l|}{ Intake of iron + folicacid } \\
\hline Do not take & $58(55.77)$ & $46(44.23)$ & \multirow{3}{*}{$0.002^{*}$} \\
\hline Not regularly & $74(60.16)$ & $49(39.84)$ & \\
\hline Takeseveryday & $24(34.29)$ & $46(65.71)$ & \\
\hline \multicolumn{4}{|l|}{ Age of the pregnancy } \\
\hline Firstterm & $2(15.38)$ & $11(84.62)$ & \\
\hline Secondterm & $48(47.06)$ & $54(52.94)$ & $0.004^{*}$ \\
\hline Thirdterm & $106(58.24)$ & $76(41.76)$ & \\
\hline Knowledge on causes of an & & & \\
\hline Yes & $55(65.5)$ & $29(34.5)$ & O \\
\hline No & $72(44.2)$ & $91(55.8)$ & \\
\hline Knowledge on anemia & & & \\
\hline Good & $14(34.15)$ & $27(65.85)$ & $0.012^{*}$ \\
\hline Poor & $142(55.47)$ & $114(44.53)$ & 0.012 \\
\hline
\end{tabular}

* Significance at 5\%

Table 3. Risk factors for anemia in pregnant women.

\begin{tabular}{lll}
\hline Variables & OR (IC at 95\%) & P-value \\
\hline Matrimonial Regime & & \\
Monogamy & $2.04(0.53-7.89)$ & $\mathrm{ns}$ \\
Polygamy & $4.21(1.04-16.99)$ & $0.023^{*}$ \\
Single/Divorced/widow & 1 & $/$ \\
Number of meals per day & & \\
$\leq$ two meals & $2.81(1.33-5.95)$ & $0.007^{*}$ \\
\hline
\end{tabular}




\begin{tabular}{lll}
\hline Variables & OR (IC at 95\%) & P-value \\
\hline $\begin{array}{l}\geq \text { three meals } \\
\text { Regular fruit consumption }\end{array}$ & 1 & $/$ \\
Yes & $0.28(0.11-0.75)$ & $0.011^{*}$ \\
No & 1 & $/$ \\
$\begin{array}{l}\text { Regular kaolin consumption } \\
\text { Yes }\end{array}$ & $1.97(1.001-3.88)$ & $0.049^{*}$ \\
No & 1 & $/$ \\
Knowledge on causes of anemia & & \\
Yes & $0.36(0.19-0.68)$ & $0.002^{*}$ \\
No & 1 & $/$ \\
Knowledge of how to prevent anemia & & \\
Yes & $0.36(0.19-0.68)$ & $0.003^{*}$ \\
No & 1 & $/$ \\
Age of the pregnancy & & \\
$1^{\text {st }}$ trimestre & $0.24(0.05-1.26)$ & $\mathrm{ns}$ \\
$2^{\text {nd }}$ trimestre & $0.03(0.28-0.92)$ & $0.014^{*}$ \\
$3^{\text {rd }}$ trimestre & 1 & $/$ \\
Intake of iron + folicacid & & \\
Does not take & $1.89(0.89-4.04)$ & $\mathrm{ns}$ \\
Not regularly & $2.90(1.42-5.95)$ & $0.014^{*}$ \\
Everyday & 1 & $/$ \\
Blood loss during pregnancy & & \\
Yes & $2.36(1.12-4.93)$ & $0.023^{*}$ \\
No & 1 & $/$ \\
\hline
\end{tabular}

From the table above, a pregnant woman from a polygamous household $(\mathrm{OR}=4.21[1.04-16.99] \mathrm{p}=0.023)$ was 4 times more at risk of anemia compared to pregnant woman single, divorced or widowed. Compared to women taking three meals or more per day, women taking up to two daily meals $(\mathrm{OR}=2.81[1.33-5.95] \mathrm{p}=0.007)$ were three times more at risk of anemia. Pregnant women who consumed kaolin $(\mathrm{OR}=1.97[1.001-3.88] \mathrm{p}=0.049)$ were twice as likely to have anemia as those who did not. Those who did not take iron and folic acid regularly $(\mathrm{OR}=2.90$ $[1.42-5.95] \mathrm{p}=0.014)$ were three times more likely to have anemia than those who used them daily. Women with blood loss during pregnancy $(\mathrm{OR}=2.36[1.12-4.93] \mathrm{p}=0.023)$ were twice as likely to have anemia as those without.

However, regular consumption of fruit $(\mathrm{OR}=0.28[0.11$ $0.75] \mathrm{p}=0.011)$ and good knowledge of the causes of anemia $(\mathrm{OR}=0.36[0.19-0,(\mathrm{OR}=0.3[0.28-0.92] \mathrm{p}=0.014)$ were significantly associated with a reduced risk of anemia among pregnant women in the Banyo Health District.

\section{Discussion}

The prevalence of anemia among pregnant women in the Banyo Health District was $52.5 \%$. These results were significantly lower than those found by Nahounou Bléyéré et al. [12] in Ivory Coast, where the prevalence of anemia was $66 \%$. On the other hand, they were similar to those reported in other studies in developing countries, notably in Malawi by Van Den [13] where it was $57.1 \%$ and in Nouakchott by Baidy et al. [14] where the prevalence was 53.1\%. However, Nguefack Tchente et al. [15] in Douala reported a significantly lower prevalence among pregnant women (39.8\%) and Yaoundé in a similar study Jutcha et al. [16] had found a prevalence two times lower $(21.36 \%)$. Furthermore, in Kano (Nigeria), Nwizu et al. [4] reported a prevalence of anemia 3 times lower (17\%) and INS, MINEPAT and MOP [7] in Cameroon in EDS-MICS found significantly lower results $(40 \%)$. Relative to severe anemia, our results were lower than those of Jutcha et al. [16]. However, they were 3 times higher than those of Nguefack Tchente et al. [16] and 5 times higher than those found by Koura et al. [17] in South Benin (1.7\%). This high prevalence of anemia among pregnant women in the Banyo Health District is explained by the fact that the majority of anemic pregnant women were from polygamous households where there are enough people to feed, where incomes are fairly modest and therefore do not feed sufficiently. In most cases, they consumed no more than 2 meals a day. Moreover, the consumption of kaolin by women who, moreover, prevents the absorption of iron could explain this frequency of anemia, but also, the irregular intake of iron during the gestational period. In addition, IPT2 was fairly low (7\%). This implies that pregnant women would be exposed to malaria and possibly anemia during pregnancy.

The vast majority of women $(80 \%)$ were between the ages of 18 and 35, therefore young. Indeed, age had no effect on haematological parameters and therefore on the occurrence of anemia in pregnant women. These results are similar to those of Demmouche and Moulessehoul [18] in Algeria and Meda et al. [19] in Burkina Faso which showed that the prevalence of anemia in women was not associated with age. On the other hand, other studies [20] showed that pregnant women under 20 years of age were twice as likely to be anemic as older women. Galan et al. [21] showed that hemoglobin increased significantly from age 35 in women.

Polygamy was identified as a risk factor for anemia in pregnant women. Indeed, a pregnant woman from a polygamous focus was 4 times more likely to be anemic (OR $=4.21, \mathrm{p}=0.023)$. In polygamous households generally, incomes are very modest and therefore the standard of living is relatively low and there are enough people to feed. As a result, women do not eat enough because the meals are not consistent for the whole family. This situation favors nutritional deficiencies and contributes to the failure to meet the nutritional needs of pregnant women and, therefore, exposes them to anemia.

The risk of anemia in pregnant women is high in women who do not regularly consume animal proteins (meat, fish, eggs), vegetable proteins (beans, soybeans) and fruits. Pregnant women who regularly consume fruits $(\mathrm{OR}=0.28, \mathrm{p}$ $=0.011$ ) were at lower risk of anemia than those who did not. Indeed, $74.5 \%$ of anemic women avoided consuming eggs and soybeans for fear of getting pregnant and suffering during childbirth. Yet the diet of the pregnant woman is very important and must be well balanced to support the mother and the fetus with the fruits to allow a good fixation of iron in the body. Indeed, the egg is a source of indispensable proteins accessible for the good development of the fetus as well as the soy which commonly called "the meat of the poor". But he finds that many women do not consume because of their ignorance, prejudice, customs and habits including fear of caesarean section and giving birth to babies 
without hair. This misperception is very detrimental to the woman and her fetus.

Geophagy (consumption of kaolin) is a common practice in some populations in Cameroon and elsewhere. The present study showed that women consuming kaolin, or kalaba (OR $=1.97, \mathrm{p}=0.049$ ) compared to non-consuming women, were twice as likely to be anemic. These results are in agreement with those of Seyrane et al. [22] who concluded that geophagy prevents intestinal absorption of iron and may be responsible for severe iron deficiency. Indeed, geophagy is a perversion of taste, and consists in searching for non-edible substances such as coal, earth, clay, soap, etc. A causal relationship between this behavior and iron deficiency has been reported in several studies because these non-food products provide chelators that prevent iron absorption. Thus, pica plays an important role in the attack of women by iron deficiency anemia or at least in its maintenance. In this sense, the removal of this practice will allow a significant correction of anemia in pregnant women.

Supplementation of pregnant women with iron-folic acid is systematic and implemented in all health facilities in Cameroon. Indeed, in most households, women do not always eat well or enough during pregnancy, hence this policy of supplementation with iron and folic acid during the pregnant period. The proportion of women taking iron supplements daily was very low (23.57\%). Regular intake of these supplements would reduce the risk of anemia because women who did not regularly take iron during pregnancy $(\mathrm{OR}=2.9, \mathrm{p}=0.014)$ were 3 times more at risk of anemia than those who were taking every day. This is justified by the fact that many accused of nausea, lack of financial resources and oblivion (forgetfulness). This fundamentally raises the problem of raising awareness among women at ANC.

In addition, anemia in women is believed to be due to certain conditions, including malaria and HIV infection. Indeed, a large proportion of pregnant women (57\%) had not taken any IPT and $18.1 \%$ of women did not sleep under a mosquito net. The absence of IPT and the non-use of ANC during pregnancy predispose women to malaria and therefore to probable anemia. A non-negligible proportion (10\%) of women was on antiretroviral therapy. Indeed, HIV-positive women are more likely to be anemic than HIV-negative women. Moreover, Mugisha et al. [23] in a prospective clinical study of a cohort of seropositive and HIV-negative women in rural areas in southwestern Uganda showed that anemia was evolving with the progression of HIV infection $(23.6 \%$ as against $12.8 \%)$.

\section{Conclusion}

The high frequency of anemia in pregnant women remains a reality and a health problem in the Banyo Health District. Many factors contribute to its occurrence in particular, noniron supplementation during pregnancy, loss of blood during pregnancy, eating habits such as the number of daily meals less than or equal to 2 and the consumption of kaolin. Indeed, despite some efforts, the prevalence of anemia among pregnant women in the Banyo Health District was $52.5 \%$, of which mild anemia was $46 \%$, moderate anemia was $48 \%$ and severe anemia $6 \%$. This health problem is of concern and reflects the need for comprehensive action to address this public health problem for the welfare of mothers and children. Thus, it is important to mobilize a preventive strategy based on sensitization, nutrition and health education of the populations and the pregnant woman specifically. Additionally, systematic martial supplementation from the second trimester of pregnancy remains imperative.

\section{Interest's Conflict}

The authors don't declare any interest's conflict.

\section{References}

[1] WHO/UNICEF. Joint statement: Focusing on anaemia, towards an integrated approach for effective anaemia control. WHO. Geneva. 2004.

[2] Paddle, J. J. Evaluation of the haemoglobin color scale and comparison with the haemococcus haemoglobin assay. Bull Organ Mond Health. 2002. 80: 813-816.

[3] Hall, A., Bobrow, E., Brooker, S., Jukes, M. and Nokes, K. Anaemia in schoolchildren in eight countries in Africa and Asia. Public health Nutr. 2001. 4: 749-756.

[4] Nwizu, E. N., Iliyasu, Z., Ibrahim S. A. and Galadanci, H. S. Sociodemographic and maternal factors in anaemia in Kano, Northern Nigeria. African Journal of Reproductive Health. 2011. 15 (4): 33-41.

[5] Brabin, B. J., Hakimi, M. and Pelletier, D. An analysis of anemia and pregnancy-related maternal mortality. Journal of Nutrition. 2001a. 131 (2S-2): 604-614.

[6] FAO. Agriculture, alimentation et nutrition en Afrique: un ouvrage de référence à l'usage des professeurs d'agriculture. FAO. 2002. ISBN: 9252038205.

[7] Demmouche, A. and Moulessehoul, S. Maternal anemia during pregnancy and iron supplementation. Antropo. 2011. 24: $21-30$

[8] OMS. Système d'informations nutritionnelles sur les vitamines et les minéraux. OMS. Genève. 2011.

[9] National Institute of Statistics, Ministry of the Economy of Planning and Town and Country Planning, Ministry of Public Health. Demographic and Health Survey and Multiple Indicators (EDS-MICS) 2011. Yaoundé, Cameroon. 2011.

[10] OMS. Système d'informations nutritionnelles sur les vitamines et les minéraux: Concentration d'hémoglobine permettant de diagnostiquer l'anémie et d'en évaluer la sévérité (WHO/NMH/NHD/MNM/11.1). OMS. Genève. 2011.

[11] Nahounou Bléyéré, M. et al. Heterogeneity of the pregnancy in the Ivory Coast. Ann Biol Clin. 2007. 65 (5): 525-532.

[12] Van Den Broeck NR. Anaemia and micronutrient deficiencies. British Medical Bulletin. 2003. 67: 149-160. 
[13] Baidy, B. L. O., Kone, Y., et Bassirou, LY. Anémie nutritionnelle de la grossesse à Nouakchott (Mauritanie). Médecine d'Afrique Noire. 1996. 43 (6).

[14] Nguefack Tchente, C. et al. Prevalence and factors associated with anemia in pregnant women attending the General Hospital in Douala. Pan African Medical Journal. 2016. ISSN: 1937-8888.

[15] Jutcha, F. D. et al. Prevalence of iron deficiency anaemia among pregnant women in Yaounde. Health Sci. Dis. 2016. 17 (1): $1-4$

[16] Koura, KG, Briand V., Massougbodji, A., Chippaux, J-P., Cot, M. et Garcia, A. Prévalence et étiologies de l'anémie chez la femme enceinte au sud Bénin au moment du changement de politique nationale de prise en charge. Med Trop. 2011. 71: 63-67.

[17] Demmouche, A. and Moulessehoul, S. Prevalence of iron deficiency anemia during pregnancy in the wilaya of Sidi Bel Abbes (western Algeria). Antropo. 2010. 21: 39-48.
[18] Meda N., Dao Y., Touré, B., Yamego, B. et al. To evaluate severe maternal anemia and its consequences: the value of a simple examination of the coloration of the palpebral conjunctiva. Health book. 1999. 9 (1): 7-11.

[19] Scholl, T. O. and Hediger, M. L. Anemia and iron deficiency anemia: compilation of data on pregnancy outcome. American Journal of Clinical Nutrition. 1994. 59 (2): 492-500.

[20] Galan P., Preziosi P., Favier A. et al. Determining factors in the status of adult women in the SU.VI.MAX study. European Journal of Clinical Nutrition. 1998. 52: 383-388.

[21] Seyrane, Y., Bernard, F., Patrick, B., and Michel, C. Iron deficiency anemia on geophagy in a rich country: case report. Swiss Medical Journal. 2012. 8: 604-606.

[22] Mugisha, J. O., Shafer, L. A., Van der Paal, L. et al. Anaemia in a rural Ugandan HIV Politic cohort: prevalence at enrollment, incidence, diagnosis and associated factors. Tropical Medicine \& International Health. 2008. 13 (6): 788794. 